\title{
Consumer Perceptions of Automated Driving Technologies: An Examination of Use Cases and Branding Strategies
}

\author{
David M. Woisetschläger
}

\subsection{Introduction}

The automated, self-driving vehicle is one of the automobile industry's major ventures in the 21 st century, driven by rapid advances in information technology [10, 11]. Technological innovations in the field of automated driving promise to contribute positively to the financial bottom line of automobile manufacturers [46]. Their integration as supplementary equipment increases the contribution margin of each car sold. In addition, automated mobility functions lay the foundations for new business models such as elaborated navigation services. While industry experts expect that it will take until the middle of the $21 \mathrm{st}$ century until fully automated cars will be available to the mass market [42, 45], automobile manufacturers have already begun to introduce supportive functions such as lane assistants and collision avoidance systems to the market $[43,50,64,66]$. The promising market predictions suggest a general openness of customers towards using self-driving cars [51]. Besides automobile manufacturers and suppliers, technology firms such as Google are pinning their hopes on the predicted potential of automated driving technology [36, 37, 43].

The emergence of technology firms as competitors poses a threat to the established car manufacturers [58], as automated driving functions may require different organizational capabilities such as information technology, and faster innovation cycles, which are typically strengths of technology firms such as Apple or Google. Recent industry reports suggest that Google, as the new market entrant, is by far the brand associated most with self-driving cars [37]. Moreover, cars not yet in existence from technological firms receive similar levels of consideration in consumer surveys to those of established car manufacturers [37]. Therefore, on the one hand, established car manufacturers are concerned about how their current market positions can be defended against potential new entrants.

D.M. Woisetschläger $(\bowtie)$

Institute of Automotive Management and Industrial Production, Technische Universität

Braunschweig, 38106 Braunschweig, Germany

(C) The Author(s) 2016

687

M. Maurer et al. (eds.), Autonomous Driving,

DOI 10.1007/978-3-662-48847-8_32 
On the other hand, cooperation with technological firms could help car manufacturers to differentiate their brands from their competitors', especially if partnerships are selective or exclusive. Announcements of partnerships, such as the cooperation between Audi and Apple, point in this direction.

At the same time, the role of branding as a critical success factor has been questioned in many instances. More precisely, the generally high relevance of brands in the context of cars has been recently put into question. Several studies suggest the diminishing role of automobiles relative to other products such as smartphones, at least for young customer segments [12]. The emergence and increasing popularity of access-based mobility systems such as car-sharing implies a trend towards a more utilitarian perspective on automobiles [57]. In contrast, some factors contributing to the high relevance of automobile brands remain relevant, irrespective of potential shifts in the preference hierarchy of product categories over time. This is because the relevance of a brand as influencing variable in a purchasing situation is generally seen as high when the purchase or use is associated with high levels of risk, information asymmetry, and symbolic value [34].

Existing literature provides comprehensive models for consumer goods, allowing an assessment of the relative importance of brands as predictor of purchasing behavior. In the particular context of high technology products, understanding of the role of brand knowledge is limited. Similarly, extensive knowledge exists about the effects of alternative brand strategies such as brand extensions (e.g., new services) or brand alliances, e.g., [68], and how new product introductions influence the parent brand perception, e.g., [2]. However, an examination for high technology products such as automated driving technology does not exist.

Against this background, this article contributes to the literature by developing a conceptual framework depicting relevant drivers of consumer acceptance and consequences of branding in the context of automated cars. Second, this article examines the relative importance of automobile manufacturer and technology brands for the acceptance of automated driving technology and services based on these technologies. Third, effects of the introduction of these technologies in a brand alliance are assessed. Fourth, the article conceptualizes how differing use-cases are perceived by potential customers. Based on the results of these empirical studies, implications for theory and management practice are derived.

\subsection{Theoretical Background}

\subsubsection{Technology-Mediated Services, Service Robots, and Consumer Acceptance}

The emerging phenomenon of assisted and automated driving has been primarily studied from technological, legal, political, and ethical perspectives (e.g., [5, 7, 14, 26 -28, 30, 35, $41,48,52,55,62])$. Automated driving is defined as the shift of vehicle control from the 
driver to the vehicle [63], while the extent of automation depends on the level of vehicle automation. The National Highway Traffic Safety Administration (NHTSA) has defined five levels of vehicle automation based on the proportion of driver vs. vehicle control. In its highest form, the vehicle performs all safety-critical driving functions and monitors roadway conditions for an entire trip, disengaging the driver from all duties [63]. The vision of fully automated driving in its highest form is seen as promising in terms of business potential, safety, and traffic management [21]. Consequently, automobile manufacturers and technological players such as Apple or Google are investing in the continuous progress of assisting and automated driving technologies. While this development seems to be promising from a consumer perspective on the one hand, literature also suggests that consumers hold strong objections against automated driving technology [25].

While relatively few research articles exist which explicitly focus on consumer perceptions of automated driving technologies (e.g., [51]), different contextual areas such as studies on self-service technologies, and service robots point at perceived benefits and problems that are associated with the shift of control from consumers to technology.

Research on consumer acceptance of technology innovations is based on the technology acceptance model and its subsequent modifications and generalizations [8, 15 17, 47, 60, 65, 67]. Four distinct factors are conceptualized as antecedents of consumer acceptance and their subsequent behavior. The first antecedent, performance expectancy, refers to the perceived value of the technology. The second variable, effort expectancy, is defined as the degree of ease associated with the use of the system [65]. Third, social influences affecting individuals' perceptions of subjective norms towards using the technology influence consumer acceptance and adoption of a new technology. Fourth, facilitating conditions such as infrastructure or support contribute to consumer acceptance. One of the most critical factors of consumer acceptance towards technology innovations and technology-mediated services is the perception of control. Even in smart-interactive or remote services which imply a limited and indirect human interaction, perceived loss of control has been found to be negatively related to consumer acceptance ([70, 71]). In addition, trust in technology-mediated services has been found to be critical, especially when the service is perceived as risky $[69,70]$. To conclude, research on technology acceptance and technology-mediated services has identified the importance of perceived value, effort, social influences, facilitating conditions such as perceived behavioral control. Trust has been identified as a key prerequisite.

In contrast to research on general technology acceptance and technology-mediated services, research on consumer perceptions of service robots is still at an early stage. The studied contexts predominantly focus on robots in smart home environments (e.g. [31, 49]) and healthcare appliances (e.g., [38]). Their research suggests that people prefer robots to act as trustworthy and controllable facilitators with a focus on interaction and cooperation rather than autonomously acting performers [23]. In a similar vein, research on robot companions suggests that people primarily see robots as assistants and serving machines with only a minority of the studied sample indicating that they would see them as peers or friends [18]. Research on robot companions recommends that the robot's role, appearance 
and behavior should be better matched to human requirements [9]. These findings point to the question of how an automated driving robot should relate to its human counterpart [54].

One central aspect of human-machine interaction is the perceived autonomy of the consumer [4,29]. While the role of consumer autonomy has been addressed directly or indirectly by some studies, its criticality for consumer acceptance of automated technologies might not be fully captured in the contexts studied. Restricting or removing the autonomy of individuals could cause reactance, i.e., negative psychological and contrary behavioral responses of consumers as reactions to a perceived restriction of their personal freedoms [6, 44]. Automated driving systems could be perceived as a threat to drivers' autonomy, and reactance could arise in terms of consumer boycott intentions or low adoption rates. Presently, it is unclear if consumers are willing to accept a loss in control [56].

In the next section, findings of consumer-based studies on automated driving technology will be briefly summarized.

\subsubsection{Research on Consumer Acceptance of Automated Driving Technology}

Only relatively few domain-specific studies exist which explicitly focus on consumer perceptions of automated driving systems. Because consumer knowledge of automated driving technology is sparse, a recent study analyzes reader comments to 15 distinct newspaper articles on automated driving in Germany and the US [25]. Their results provide evidence for the implied value propositions of flexibility and comfort, and comments relating to the safety and reliability of automated driving technology. The US comments in particular show negative responses relating to the restriction of freedom, pointing at the high relevance of consumer autonomy.

A second study that focuses on the contexts of automated medical diagnosis systems and automated driving provides descriptive evidence for the important role of prominent brands as risk-reducing mechanism [13]. Four distinct scenarios of future mobility are developed in a study using a set of experts from car manufacturers, public authorities, scientists, and environmental groups [19]. Two of the four scenarios relate to automated driving and distinguish between privately owned and access-based ("shared") automated vehicles. Both scenarios perform worse on the individualistic performance relative to the status quo, while performance advantages are seen on the systemic dimension.

A first study quantifying the effects of psychological antecedents on usage and purchase intentions finds generally positive values for usage intentions among a sample of 421 French consumers [51]. Their findings suggest significant positive influences of the general attitude towards automated driving, acceptability, and sensation (i.e., novelty) seeking on usage intentions. In addition, they find a gender effect revealing higher usage intentions for males. The latter effect is in line with existing literature on technology adoption, which generally finds male consumers to be more likely to be early adopters. 
The present study attempts to build on these findings and conceptualizes a model which considers the key variables discussed in this section, the role of branding, and different use cases of automated driving. In the next chapter, the effects of brand equity, brand alliances, and different use cases on purchase intention are discussed.

\subsection{Conceptual Model}

\subsubsection{Brand Equity, Acceptance Drivers and Purchase Intention of Automated Cars}

Brand equity (BE), defined as the added value endowed by the brand to the product [20], is regarded as an important concept for both business practice and academic research. Companies can gain competitive advantage through successful brands because they offer opportunity for differentiation, increased customer loyalty, and the possibility for charging price premiums [39]. Strong brands are characterized by measurable differences of what consumers know about these brands. According to Keller [33], consumer-based brand-knowledge consists of two dimensions, brand awareness and brand image. Brand awareness refers to the strength of a brand in memory, and the likelihood and ease with which the brand will be recognized or recalled under various conditions [59]. Brand image is defined as the perception of a brand as reflected by the brand associations held in consumer memory [33]. The favorability, strength, and uniqueness of brand image permit the brand to be strategically differentiated and positioned in the consumer's mind.

Brand equity has been found to be positively related to customer loyalty and willingness to pay. While strong brands are generally helpful for the marketing of products and services, the importance of brands has been found to vary across industry sectors, with a high relevance for the marketing of automobiles [22]. The relevance of branding strongly depends on the function of the brand as risk reducing factor, its function to enhance information efficiency, and its symbolic value. Since the purchase of a new car is an extensive decision involving comparably high expenditures and the collection of extensive information, strong brands can promote the purchasing process.

Besides the sparse empirical evidence for the risk-reducing effects of strong brands in the context of automated driving [13], the aforementioned brand functions should be positively related to consumer acceptance of automated driving systems. Knowledge and experience of consumers with automated driving technology is marginal. In combination with additional cost for automated driving abilities, consumers are likely to evaluate a purchase decision as risky. Strong brands can effectively help to reduce perceptions of risk.

In addition to a distinction between strong and weak automobile and tech-brands, introducing the respective automated driving system, several additional antecedents are considered in accordance to the aforementioned literature. More precisely, functional trust, the perceived convenience of the system, the price-value ratio, and the symbolic 
value of the system explain why consumers feature high/low levels of purchase intentions. These factors are likely to be influenced by the consumers' perceptions of safety and security of the system, the perceived autonomy, their privacy concerns [3], and brand attitude.

To control for differences on a consumer level which are independent from the presented scenario, the affinity of individuals towards adopting innovations, autonomy preference, and brand possession are considered below.

\subsubsection{Brand Alliances and Purchase Intention of Automated Cars}

Besides introducing automated driving systems under the brand of a single automobile manufacturer or tech-firm alone, brand alliances are another option to consider. Brand alliances have become more frequent in a wide variety of industries [40]. One of the most significant findings in brand alliance research is that an unknown or unfavorable brand can benefit from joining an alliance with a known and favorable brand [53, 61]. Brand alliances consist of at least two brand entities. Horizontal and vertical brand alliances can be distinguished [1]. Vertical brand allies play different roles in the value chain (e.g. Intel as the supplier and Dell as the manufacturer), whereas horizontal brand allies belong to the same industry or similar product category (e.g. Häagen-Dazs and Baileys). For the present study, a vertical brand alliance between, e.g., an automobile brand and a tech-company is proposed to be a realistic scenario, as more and more alliances between car manufacturers and tech-companies have been announced in the media [32, 37]. Differences in purchase intentions depending on the presence/absence of a brand alliance of a strong/weak automobile manufacturer brand with a strong tech-brand will be assessed.

\subsubsection{Use Cases of Automated Driving and Their Effects on Purchase Intention}

As mentioned above, the National Highway Traffic Safety Administration (NHTSA) distinguishes five levels of vehicle automation based on the proportion of driver vs. vehicle control [63]. To assess potential differences in purchase intention, different use cases which are comparable to automated driving on the fourth level of full self-driving automation are considered. In detail, the first study exposes the subjects to Interstate Pilot with Extended Availability Through Driver. While the second study extends Study 1 by considering brand alliances, two additional use cases are introduced in Study 3. The second use case is Automated Valet Parking and reflects comparably lower levels of personal physical risk and lower levels of personal autonomy loss. The third use case is on the fifth level of the NHTSA typology and suspends the driver from driving. The vehicle is a Vehicle on Demand. It is expected that the third use case is evaluated most critically, as it could involve higher levels of personal physical risk and a restraint of personal autonomy. 


\subsection{Sample Description}

The proposed model is split into a series of three studies and tested via an online consumer survey among members of an online panel provider. The sample was selected based on the requirements of holding a valid driver license, possession of a car, and comparability in terms of gender and age according to the German population between 18 and 70. Prior to the manipulation, respondents were asked to name the brand and model of the car that they would use primarily. In addition, they were questioned about their involvement in cars in general and had to indicate their familiarity with and attitude towards the brand(s) used in the respective scenario. Each subject was then randomly assigned and confronted with only one scenario. An Interstate Pilot was featured as automated driving system in the first two studies. Study three explicitly examines how consumers perceive alternative use cases (Automated Valet Parking, Vehicle on Demand). After exposure to one of the scenarios, respondents were asked to indicate their purchase intention for the optional automated driving system. Next they were asked to rate several factors that were hypothesized to be either positively or negatively related to their intention to consider the Interstate Pilot on offer. The survey concluded with manipulation checks, a self-assessment of the respondents driving capabilities, stress perception, subjective feelings about safety in traffic, and socio-economic characteristics of the respondents. The final sample contains 545 responses. $55.2 \%$ of the respondents are male, the average age of the respondents is 42.83 $($ standard deviation $(\mathrm{SD})=12.62)$.

\subsection{Study 1}

\subsubsection{Study Design, Data Collection, and Measures}

The first study attempts to test the effects of brand equity on consumer acceptance using a laboratory experimental design, in which we asked respondents to read a fictitious press release indicating the announcement of Interstate Pilot Using Driver for Extended Availability. In order to isolate potential effects of brand equity differences (i.e., strong vs. weak brands) and potential differences in credibility of the actors (i.e., automobile firms vs. new market entrants), different press releases for different players were designed. A $2 \times 2$ between-subjects experimental design was constructed in which the different scenarios only differ in terms of the selected brand, while everything else is held constant. Figure 32.1 shows the press release used in the first study.

In total, 239 respondents took part in Survey 1. The participants are roughly equally distributed across the two additional scenarios. Cell-sizes ranged from 49 to 65 respondents and no differences in age and gender distribution were found across cells. To test if the manipulations of different levels of brand equity and competence of the industry actors were perceived differently by the respondents, manipulation checks were conducted. To examine if the respondents perceived the brands differently, brand attitude was measured as 


\author{
| News | Automobile Sector | Newsflash | \\ June 8th 2014 \\ 09:45 MESZ
}

[Brand] presents automated driving on highways - market launch by the middle of 2015

Berlin (dpa). As [brand] announced today, an optional module named ADX ("Automated Driving Experience") will be offered in the course of the yearly car updates by the middle of 2015. The module will be offered for all car models of [brand] and allows fully automated driving on all German highways.

The driver can activate the ADX system on the highway with a simple push of a button. The ADX is linked to the navigation system and takes over any preset target. All driving functions will be taken over by ADX at a manually adjustable speed up to $160 \mathrm{~km} / \mathrm{h}$. "The driver becomes a passenger and can use the time to relax or for work," said Herbert Mueller, chairman of [brand]. Nevertheless, the driver can intervene at any time and take-over the control from the system. Prior to reaching the last exit before the target destination, an acoustic signal indicates the driver to take over control. The engineers of [brand] have also thought about the fact that drivers could fall asleep. If no reaction is monitored by the system after prompting twice, the car will pass the exit and drive automatically to the next rest area, where the car will be safely parked.

ADX will be available by the middle of $\mathbf{2 0 1 5}$ as optional component for all car models of [brand] for a price of $€ \mathbf{3}, \mathbf{5 0 0}$. "By introducing automated driving on highways, [brand] provides a valuable contribution to the increase of safety on German streets," the car-manager pointed out.

Fig. 32.1 Fictitious press release used in Study 1. Image rights belong to the author

the manipulation check variable. Brand attitude reflects the favorability and strength of brand associations, one of the two dimensions of brand equity. As automobile brands generally perform well in brand awareness (recall or recognition) scores, brand attitude is a more reliable variable to measure differences in brand equity. Brand attitude was measured with three items, capturing the favorability, likability, and performance of the brand. Results reveal significant differences between the strong (mean value $(\mathrm{MV})=5.40$; $\mathrm{SD}=1.44)$ and weak $(\mathrm{MV}=4.55 ; \mathrm{SD}=1.55)$ car manufacturer brands $(p<0.05)$ and the strong $(\mathrm{MV}=5.54 ; \mathrm{SD}=0.99)$ and weak $(\mathrm{MV}=3.75 ; \mathrm{SD}=1.79)$ technology brands $(p<0.01)$. In addition to the manipulations, brand possession and differences in individual innovativeness were included as co-variables. The dependent variable purchase intention was measured with three items indicating each individual's likelihood to purchase/consider a car with the particular brand and Interstate Pilot (for the indicated price of $€ 3500$ ). The price was set in analogy to current prices for combined systems for assisted driving. The scale displays excellent reliability (Cronbach's $\alpha=0.94$ ).

To explain the reasons for varying levels of purchase intentions, several proposed drivers and barriers were measured on a perceptual level. Respondents were asked to evaluate the proposed value of the system (i.e., convenience). In addition, functional trust, price/value ratio, and prestige were included as mediators. These mediators are influenced by autonomy perceptions, autonomy preference, privacy concerns, safety and security perceptions, and brand attitude. The model also controls for brand possession and if respondents considered themselves to be early or late adopters of innovations. The results of the confirmatory factor analyses (CFA) suggest valid and reliable scales. In addition, 
the discriminant validity of the constructs was assessed [24]. The average variance extracted (AVE) for each construct exceeds the shared variance with all other constructs. Hence, we conclude sufficient reliability and validity for the measures in this study. The measurement properties and scale items are available upon request.

\subsubsection{Results}

On average, intentions to purchase the optional Interstate Pilot Using Driver for Extended Availability are evaluated to be modest ( $\mathrm{MV}=3.30 ; \mathrm{SD}=1.81)$, a finding which in line with generally high skepticism towards the adoption of innovations. From the 239 respondents who were confronted with one of the four scenarios, a total of $17.2 \%$ indicates high or very high intentions to purchase the featured automated driving system. However, more than a third of the respondents $(39.1 \%)$ of the sample replied that they would be (highly) unlikely to adopt this system in the near future. These findings indicate that there is a significantly sized market segment of early adopters but reveals acceptance problems at the same time. Therefore, the next step assesses whether these findings differ depending on the provider's brand equity and industry sector.

An analysis of variance (ANOVA) was conducted to test the hypothesized effects. The ANOVA results show a significant main effect for brand equity $(p<0.01)$, and non-significant effects for the industry sector of the firm (i.e., automobile manufacturer vs. tech company) and the interaction term. In addition, differences in individuals' general innovation affinity and car possession significantly explain differences in the observed levels of purchase intention. The effects of the manipulations on purchase intention are displayed in Fig. 32.2.

The findings indicate that purchase intention is influenced by brand equity, irrespective of the affiliation of the respective company to the sector of automobile manufacturers or tech-companies. The values for the strong automobile brand (MV = 3.67; SD = 1.91) and the strong tech-brand $(\mathrm{MV}=3.63 ; \mathrm{SD}=1.70)$ are on a similar level. In a similar vein, the difference in purchase intentions for the comparably weaker automobile brand $(\mathrm{MV}=3.01 ; \mathrm{SD}=1.81)$ and the weaker tech brand $(\mathrm{MV}=2.88 ; \mathrm{SD}=1.82)$ is insignificant as well.

To shed light on the relative impact of antecedents of purchase intention, a structural equation model was estimated. The results reveal that functional trust is the most relevant driver of purchase intention $(\beta=0.432 ; p<0.01)$, followed by the perceived convenience of the described interstate pilot $(B=0.237, p<0.01)$. The other mediators are significant, but less important (price-value ratio $\beta=0.124, p<0.05$; symbolic value $\beta=0.117$, $p<0.05$; and general innovation affinity $\beta=0.169, p<0.01$ ). In total $67.9 \%$ in variance of purchase intention are explained.

Functional trust is significantly and positively influenced by safety and security perceptions $(\beta=0.383, p<0.01)$, perceived autonomy $(\beta=0.327, p<0.01)$, general innovation affinity $(\beta=0.163, p<0.01)$, and brand attitude $(\beta=0.130, p<0.01)$. 




Fig. 32.2 Purchase intention for Interstate Pilot offered by different brands. Bildrechte: Urheberrecht beim Autor

Autonomy preference is significantly negatively related to purchase intention $(\beta=-0.138$, $p<0.01)$. Contrary to expectations, differences in privacy concerns are not significantly related to purchase intention $(\beta=0.012, p>0.1)$. These factors explain a total of $71.8 \%$ in variance of functional trust. The key value proposition of Interstate Pilot is positively affected by respondents' perceptions of autonomy $(\beta=0.598, p<0.01)$, and negatively by autonomy preference $(\beta=-0.298, p<0.01)$. Brand attitude $(\beta=0.238, p<0.01)$ is positively related to convenience perception, while all other factors remain insignificant. The antecedents explain $63.3 \%$ in variance of convenience. Similarly, the price-value ratio is strongly affected by autonomy $(\beta=0.450, p<0.01)$ and autonomy preference $(\beta=-0.122, p<0.05)$. Moreover, innovation-oriented consumers evaluate the price-value ratio more favorably $(\beta=0.241, p<0.01)$. Brand attitude is also positively related to price-value perceptions $(\beta=0.131, p<0.05)$. A total of $42.8 \%$ in variance of price-value ratio are explained by the model. Symbolic value is significantly affected by differences in brand attitude $(~(=0.575, p<0.01)$, explaining a total of $33.1 \%$ in variance.

The results of the first study offer relevant insights into the drivers of purchase intention of Interstate Pilot Using Driver for Extended Availability. Prior to convenience, functional trust is seen as the most critical factor affecting consideration of the system. Besides promoting the central value proposition (i.e., convenience value), marketing managers should emphasize the perceptions of safety, security, and autonomy, since these variables are indirectly related to the key outcome variable, purchase intention. Strong brands can promote the adoption of automated driving on highways, as differences in brand attitude are positively related to symbolic value, price-value perceptions, convenience, and functional trust. As shown above, the respondents were not found to distinguish between 
automobile and tech-brands in general, but rather between strong and weak brands. Hence, strong tech-brands like Apple or Google can significantly endanger the position of established manufacturers, especially those with weak brands. Therefore, Study 2 analyzes if a weak (strong) automobile brand can benefit from joining a brand alliance with a strong tech brand.

\subsection{Study 2}

\subsubsection{Study Design, Data Collection, and Measures}

The second study attempts to test if consumer acceptance is different when the automated driving system on offer is branded by the OEM and a technology partner, constituting a brand-alliance. The brand alliance settings are compared to the results of the single-brand strategies documented in Study 1. Similarly to Study 1, each respondent was exposed to one of the two additional scenarios, in which we asked respondents to read a fictitious press release indicating the announcement of an Interstate Pilot Using Driver for Extended Availability. The press release was modified by adding the second brand name into the header and by integrating both brand names into the text.

The proposed model was tested via an online consumer survey among members of an online panel provider. The same sample selection criteria were used as documented in Study 1 above and the survey had the identical structure.

In addition to the participants in the first study, 92 respondents took part in the survey for Study 2. The participants were distributed roughly equally across the two additional scenarios. Cell-sizes ranged from 45 to 47 respondents and no differences in age and gender distribution were found across cells. Manipulation checks of brand attitude reveal significant differences $(p<0.01)$ between the strong automobile brand ( $\mathrm{MV}=5.35$; $\mathrm{SD}=1.62)$ and the weak automobile brand ( $\mathrm{MV}=4.74$; $\mathrm{SD}=1.49)$. In addition, the tech brand used in the brand-alliance scenarios is evaluated significantly better than the weak automobile brand, whereas the difference to the strong automobile brand is insignificant $(\mathrm{MV}=5.50 ; \mathrm{SD}=1.01)$.

Similarly to Study 1 , purchase intention was measured with three items and the same co-variables were included. The structural model was also replicated in order to identify possible explanatory variables for the observed differences in purchase intention. The measurement properties suggest valid and reliable scales.

\subsubsection{Results}

An analysis of variance (ANOVA) was conducted to test the hypothesized effects. The ANOVA results show a significant main effect for co-branding $(p<0.01$ ), and a significant effect of innovation affinity on purchase intention. The results show a 
significant negative effect of co-branding on purchase intention. The dependent variable drops from 3.67 to 2.67 ( $\mathrm{SD}=1.93$ ) for the strong car brand, and from 3.01 to 2.78 $(\mathrm{SD}=1.80)$ for the weak car brand. With regard to the results of the manipulation check, these findings are against expectations. At least for the weak car-brand, positive supporting effects of being linked to a more attractive tech-brand would have been plausible. To analyze potential explanations for the observed effects, a structural equation model was estimated. The results exhibit significant differences to the model reported in Study 1. In detail, functional trust plays an even more important role for purchase intention in the case of a brand alliance between an automobile brand and a tech brand $(\beta=0.747, p<0.01)$. Price-value ratio also shows a significant effect on purchase intention $(\beta=0.180$, $p<0.01$ ), while all other remaining direct effects are insignificant. In addition, the impact of safety and security perceptions on functional trust is larger in the brand-alliance setting $(\beta=0.550, p<0.01)$. Autonomy perceptions also have a significant but comparably smaller effect on functional trust $(\beta=0.208, p<0.05)$.

These findings suggest that consumers' evaluations of the automated driving system are not improved by a co-branding strategy with a tech brand, which is evaluated similarly or better relatively to the automobile brand. Rather, consumers form their purchase intention based on the trustworthiness of the system, which is mainly influenced by their safety and security concerns and the perception of autonomy. In the case of the strong car brand, the safety and security of the automated driving system are evaluated significantly more negatively $(p<0.05)$ in a brand alliance with a tech brand $(\mathrm{MV}=4.15 ; \mathrm{SD}=1.82)$ relative to a single-brand strategy $(\mathrm{MV}=4.94 ; \mathrm{SD}=1.65)$. For the weak car brand, this effect is insignificant. Overall, the findings of Study 2 indicate that automobile manufacturers and technology firms such as Apple or Google need to emphasize the specific benefits of potential brand alliances. Consumers perceive such partnerships as riskier and functional trust becomes a prerequisite of the adoption of automated driving systems.

In order to test the generalizability of these findings, Study 3 replicates Study 2 using two alternative use cases of automated driving.

\subsection{Study 3}

\subsubsection{Study Design, Data Collection, and Measures}

The third study attempts to measure differential effects of alternative scenarios of automated driving, each branded with a weak or strong brand. In addition to the Interstate Pilot Using Driver for Extended Availability used as stimulus in the first and second study, two scenarios reflecting low personal risk (Autonomous Valet Parking) and high personal risk (Vehicle on Demand) were designed. Table 32.1 shows the press releases used in the third study.

A strong and a weak OEM-brand were both used as single brands, constituting two scenarios for each additional use-case. Similarly to studies 1 and 2, each respondent was 
Table 32.1 Use case descriptions utilized in Study 3

Use case 2: fully automated vehicle, low personal risk (Autonomous Valet Parking)

[Brand] presents fully automated parkingmarket launch by the middle of $\mathbf{2 0 1 5}$

Berlin (dpa). As [brand] announced today, an optional module named APT ("Automated Parking Technology") will be offered in the course of the yearly car updates by the middle of 2015. The module will be offered for all car models of [brand] and allows fully automated parking

The driver can simply leave the car at the target destination and activate the APT system via smartphone. APT will independently search for a parking space at no charge within a radius of $5 \mathrm{~km}$. All driving functions will be taken over by APT at a manually adjustable speed of up to $30 \mathrm{~km} / \mathrm{h}$. "Drivers can directly reach their targets in city centers, the car takes care of the parking task," said Herbert Mueller, chairman of [brand]. After a business appointment or a visit to a theater, the car can be activated and ordered to any location via smartphone. The car remains locked for third parties throughout the process, with the exemption of the Police

APT will be available by the middle of $\mathbf{2 0 1 5}$ as an optional component for all car models

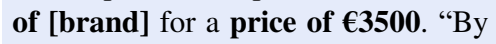
introducing fully automated parking, [brand] provides a valuable contribution to stress reduction when searching for scarce parking spaces," the car manager pointed out
Use case 3: fully automated vehicle, high personal risk (Vehicle on Demand)

[Brand] presents fully automated drivingmarket launch by the middle of $\mathbf{2 0 1 5}$

Berlin (dpa). As [brand] announced today, an optional module named ADR ("Automated Driving Robot") will be offered in the course of the yearly car updates by the middle of 2015. The module will be offered for all car models of [brand] and allows fully automated driving on all German streets

The communication between passenger and car is realized by the navigation system. After entering the target destination, the car is moved automatically by the system, allowing no steering actions by the passenger. Only the target destination can be modified and an emergency stop function allows a safe stop and exit. All driving functions will be taken over by ADX at a manually adjustable speed of up to $160 \mathrm{~km} / \mathrm{h}$. "The driver becomes a passenger and can use the time to relax or for work," said Herbert Mueller, chairman of [brand]. "Our research has shown that driving robots react more reliably in dangerous situations than human drivers," Müller continued. Especially after a period of inactivity, the danger of overreacting passengers would be high, therefore [brand] would consequently rely on fully automated driving. Nevertheless, the engineers of [brand] have also thought about emergency situations. Passengers can intervene at any time. The ADR will then approach a secure stopping point

ADR will be available by the middle of 2015 as an optional component for all car models of [brand] for a price of $\mathbf{\epsilon 3 5 0 0}$. "By introducing fully automated driving, [brand] provides a valuable contribution to the increase of safety on German streets," the car manager pointed out

exposed to one of the four additional scenarios, in which the respondents were asked to read a fictitious press release indicating the announcement of Autonomous Valet Parking or Vehicle on Demand. 
The proposed model was tested via an online consumer survey among members of an online panel provider. The same sample selection criteria were used as documented in Studies 1 and 2 and the survey had the identical structure.

In total, 342 respondents constitute the sample for the third study. The participants are roughly equally distributed across the six scenarios (three use cases * strong/weak brand). Cell-sizes ranged from 49 to 65 respondents and no differences in age and gender distribution were found across cells. In accordance to the prior studies, purchase intention was measured with three items and the same co-variables were included. The structural model was also replicated in order to identify possible explanatory variables for the observed differences in purchase intention. The measurement properties suggest valid and reliable scales.

\subsubsection{Results}

The two additional use cases are perceived slightly differently relative to the Interstate Pilot Using Driver for Extended Availability used in the studies 1 and 2. On average, the intention to purchase a fully automated parking assistant is about similar ( $\mathrm{MV}=3.59$; $\mathrm{SD}=1.93$ ), whereas the fully automated driving robot receives significantly lower evaluations ( $\mathrm{MV}=2.97$; $\mathrm{SD}=1.83$ ). A share of $18.6 \%$ of the 113 respondents who were asked to evaluate the fully automated parking assistant indicates very high or high intentions to purchase the system. This is slightly higher than the $17.2 \%$ of the respondents which indicated a (very) high likelihood to purchase Interstate Pilot as featured in Study 1. The share of $38.9 \%$ of the respondents stating that they are (very) likely to refuse to buy the featured automated parking assistant is on the same level as the share of skeptics in Study 1. As the comparison of the mean values of purchase intentions already suggests, the share of respondents with (very) high intentions to purchase a fully automated driving robot is much lower $(10.9 \%)$. Nearly half of the sample of 101 respondents stated that they are (highly) unlikely to purchase the featured system in the near future. These findings point to differences in purchase intentions caused by the different use cases. In a next step, the effects of the use case and of brand equity are assessed in an ANOVA. The results reveal a significant main effect of use case $(p<0.05)$, while the main effects of brand equity and the interaction term remain insignificant.

To analyze potential explanations for the observed differences, a multi-group structural equation model was estimated. The results exhibit significant differences of the model depending on the respective use case. More specifically, the relative importance of functional trust $(B=0.170, p<0.1)$ and prestige $(B=0.08, p>0.1)$ are much lower or insignificant in case of a fully automated parking assistant. The effect of price-value ratio is slightly higher $(\beta=0.146, p<0.1)$ and innovation affinity is much less relevant $(\beta=0.122, p<0.1)$. The most relevant driver of purchase intention is perceived convenience $(\beta=0.445, p<0.01)$. The formation of functional trust, however, depends more strongly on the evaluation of safety and security $(\beta=0.469, p<0.01)$ and autonomy 
preference $(\beta=-0.165, p<0.1)$, whereas all other antecedents remain at comparable effect sizes. In addition, the evaluation of convenience as a central value proposition depends more strongly on whether respondents value the autonomy obtained from automated parking $(\beta=0.640, p<0.01)$ and if their general autonomy preference is high $(\beta=-0.436, p<0.01)$. In sum, the successful introduction of a fully automated parking assistant primarily depends on a suitable communication of its convenience value. In comparison to the other use cases, functional concerns play a less important role.

The intention to buy a fully automated driving robot depends strongly on functional trust $(\beta=0.477, p<0.01)$. Furthermore, the perceived symbolic value is a more relevant antecedent of purchase intention $(\beta=0.254, p<0.05)$, relative to the other two use cases. The perception of convenience and the remaining antecedents are less relevant. The evaluation of functional trust is formed differently than in the other two use cases. While safety and security concerns show a weaker influence on functional trust $(B=0.256$, $p<0.05)$, perceptions of autonomy $(\beta=0.447, p<0.01)$ and autonomy preference $(\beta=-0.260, p<0.01)$ reveal strong effects. The formation of convenience perceptions is by far less dependent on the perception of autonomy ( $\beta=0.380, p<0.01$ ), but relies significantly more on autonomy preferences $(\beta=-0.394, p<0.01)$. The results indicate strong self-selection effects, as consumers preferring high degrees of autonomy will refrain from purchasing a fully automated driving robot. In light of the low level of purchase intention, this scenario appears to be unattractive for most respondents.

\subsection{Discussion and Future Research}

The results obtained from the three experimental studies offer valuable insights into drivers of individuals' purchase intention of automated cars. In contrast to the generally positive values for usage intentions reported in a French study [51], the present analysis reveals that Germans are — on average — quite skeptical towards automated driving technologies. As the two studies differ considerably in terms of the methodology applied and the amount of information given to the respondents, an interpretation of differences on a national level is not possible. However, every sixth respondent indicates very high or high intentions to purchase Interstate Pilot or Autonomous Valet Parking, irrespective of the limited information available. Every tenth person even considers high purchase intentions for fully automated driving robots (vehicle on Demand) which were said to exclude the passenger from any driving operations. These figures are comparable to other consumer studies measuring consideration values for technology innovations before market introduction. If the described systems are perceived as useful and reliable after their introduction, acceptance figures are expected to rise over time.

Irrespective of the psychological value dimensions influencing purchase consideration levels, differences in the general innovation affinity partially explain why consumers consider purchasing the featured automated driving systems. In addition, respondents with high levels of autonomy preference react more negatively towards this technology. 
Besides autonomy preference, differences in autonomy perception resulting from the use cases also account for the observed variance in purchase intention. Providers of automated cars must therefore carefully segment their target markets and keep non-automated car offers for the conservative segments.

The remaining findings of the three studies and the resulting conclusions are summarized in Table 32.2.

The present study also has several limitations, which can be seen as a venue for future research. First, the empirical study was conducted based on a representative sample of the German population according to age and gender distribution. However, respondents were asked to indicate their purchase intention not relating to their currently owned car brand. Instead, they were asked to state their purchase intention towards a specific offer of a brand. Potential differences caused by brand possession and brand attitude were controlled in the model. Nevertheless, future research should attempt to focus on specific car segments with the corresponding target group to obtain more realistic results. Second, the nature of the laboratory experiment implies high levels of internal validity, but limited external validity. Future studies should strive towards a more realistic and vivid communication of the nature of automated driving, e.g., by using video stimuli rather than press releases employed in the present article. Third, future research should study how critical incidents resulting from automated driving are perceived by consumers and how their perceptions interrelate with the involved brand. Fourth, the study should be replicated in other settings (i.e., countries) to explore its boundary conditions.

Table 32.2 Summary of results and conclusions

\begin{tabular}{|c|c|c|}
\hline Scope of analysis & Results & Implications \\
\hline $\begin{array}{l}\text { Brand equity and } \\
\text { firm sector }\end{array}$ & $\begin{array}{l}\text { - Brand equity is positively related } \\
\text { to purchase intentions, } \\
\text { irrespective of the firms' } \\
\text { industry sector }\end{array}$ & $\begin{array}{l}\text { - Strong technology brands could } \\
\text { reveal similar acceptance levels } \\
\text { and are therefore a threat to } \\
\text { existing automobile brands }\end{array}$ \\
\hline $\begin{array}{l}\text { ll brand } \\
\text { es }\end{array}$ & $\begin{array}{l}\text { - Negative perception of brand } \\
\text { alliances } \\
\text { - Functional trust, which is mainly } \\
\text { influenced by safety and security } \\
\text { concerns, explains the negative } \\
\text { evaluation of vertical brand } \\
\text { alliances }\end{array}$ & $\begin{array}{l}\text { - Functional trust is a core brand } \\
\text { asset of automobile brands } \\
\text { - Safety and security concerns } \\
\text { related to tech partners must be } \\
\text { solved prior to engaging in brand } \\
\text { alliances }\end{array}$ \\
\hline $\begin{array}{l}\text { Use case differences } \\
\text { - Interstate Pilot with } \\
\text { Extended } \\
\text { Availability } \\
\text { Through Driver } \\
\text { - Automated Valet } \\
\text { Parking } \\
\text { - Vehicle on Demand }\end{array}$ & $\begin{array}{l}\text { - Consideration: } 17.2 \% \text {, mainly } \\
\text { driven by functional trust and } \\
\text { convenience (case } 1 \text { ) } \\
\text { - Consideration: } 18.6 \% \text {, } \\
\text { mainly influenced by } \\
\text { convenience (case } 2 \text { ) } \\
\text { - Consideration: } 10.9 \% \text {, primarily } \\
\text { affected by functional trust and } \\
\text { symbolic value (case } 3 \text { ) }\end{array}$ & $\begin{array}{l}\text { - Reliability concerns and the } \\
\text { perceptions of usefulness need } \\
\text { to be addressed } \\
\text { - Communication of benefits } \\
\text { derived from the system } \\
\text { - Reliability and security concerns } \\
\text { are the main barriers, } \\
\text { communication of symbolic } \\
\text { benefits suggested }\end{array}$ \\
\hline
\end{tabular}


Open Access This chapter is distributed under the terms of the Creative Commons Attribution 4.0 International License (http://creativecommons.org/licenses/by/4.0/), which permits use, duplication, adaptation, distribution and reproduction in any medium or format, as long as you give appropriate credit to the original author(s) and the source, a link is provided to the Creative Commons license and any changes made are indicated.

The images or other third party material in this chapter are included in the work's Creative Commons license, unless indicated otherwise in the credit line; if such material is not included in the work's Creative Commons license and the respective action is not permitted by statutory regulation, users will need to obtain permission from the license holder to duplicate, adapt or reproduce the material.

\section{References}

1. Aaker D (1996) Building Strong Brands. New York: Free Press.

2. Albrecht CM, Backhaus C, Gurzki H, Woisetschläger DM (2013) Drivers of Brand Extension Success: What Really Matters for Luxury Brands. Psychology \& Marketing 30(8), 647-659.

3. Araujo L, Mason K, Spring M (2012) Self-driving cars: A case study in making new markets, Lancaster University.

4. Arras KO, Cerqui D (2005). Do we want to share our lives and bodies with robots? A 2000 people survey (No. LSA-REPORT-2005-002).

5. Beiker SA (2012) Legal Aspects of Autonomous Driving. Santa Clara L. Rev. 52(4), 1145-1156.

6. Brehm JW, Brehm SS (1981) Psychological reactance: A theory of freedom and control. San Diego, CA: Academic Press.

7. Berger C (2012) From Autonomous Vehicles to Safer Cars: Selected Challenges for the Software Engineering. In Computer Safety, Reliability, and Security. Springer Berlin Heidelberg, 180-189.

8. Bitner MJ, Ostrom AL, Meuter ML (2002) Implementing Successful Self-Service Technologies. The Academy of Management Executive 16(4), 96-108.

9. Broadbent E, Stafford R, MacDonald B (2009) Acceptance of Healthcare Robots for the Older Population: Review and Future Directions. International Journal of Social Robotics 1(4), 319-330.

10. Brynjolfsson E, McAfee A (2012) Winning the Race with Ever-Smarter Machines. MIT Sloan Management Review 53(2), 53-60.

11. Burns LD (2013) Sustainable mobility: A vision of our transport future. Nature 497(7448), 181-182.

12. Cairns S, Harmer C, Hopkin J, Skippon S (2014) Sociological perspectives on travel and mobilities: A review. Transportation research part A: policy and practice 63, 107-117.

13. Carlson MS, Desai M, Drury JL, Kwak H, Yanco HA (2013). Identifying Factors that Influence Trust in Automated Cars and Medical Diagnosis Systems.

14. Chen H, Gong X, HU YF, LIU QF, GAO BZ, GUO HY (2013) Automotive Control: the State of the Art and Perspective. Acta Automatica Sinica 39 (4), 322-346.

15. Curran JM, Meuter ML, Surprenant CF (2003) Intentions to Use Self-Service Technologies: AConfluence of Multiple Attitudes. Journal of Service Research 5 (3), 209-224.

16. Curran JM, Meuter ML (2005) Self-service technology adoption: comparing three technologies. Journal of Services Marketing 19(2), 103-113.

17. Dabholkar PA, Bagozzi RP (2002) An Attitudinal Model of Technology-Based Self-Service: Moderating Effects of Consumer Traits and Situational Factors. Journal of the Academy of Marketing Science 30(3), 184-201. 
18. Dautenhahn K, Woods S, Kaouri C, Walters ML, Koay KL, Werry I (2005) What is a Robot Companion-Friend, Assistant or Butler?. In Intelligent Robots and Systems, 2005 (IROS 2005). 2005 IEEE/RSJ International Conference, 1192-1197.

19. Epprecht N, von Wirth T, Stünzi C, Blumer YB (2014) Anticipating transitions beyond the current mobility regimes: How acceptability matters. Futures 60, 30-40.

20. Farquhar PH (1989) Managing Brand Equity. Marketing Research, 1, 24-33 (September).

21. Fagnant DJ, Kockelman, K (2014) Preparing a Nation for Autonomous Vehicles: Opportunities, Barriers and Policy Recommendations for capitalizing on Self-Driven Vehicles. Transportation Research 20.

22. Fischer M, Hieronymus F, Kranz M (2002) Markenrelevanz in der Unternehmensführung Messung, Erklärung und empirische Befunde für B2C-Märkte. Arbeitspapier Nr. 1, Marketing Centrum Münster und McKinsey.

23. Flemisch F, Kelsch J, Löper C, Schieben A., Schindler J ,Heesen, M (2008) Cooperative Control and Active Interfaces for Vehicle Assistance and Automation. In FISITA World automotive Congress.

24. Fornell C, Larcker DF (1981) Evaluating structural equation models with unobservable variables and measurement error. Journal of Marketing Research, 18(1), 39-50.

25. Fraedrich E, Lenz B (2014) Automated Driving - Individual and Societal Aspects Entering the Debate. Transportation Research Record: Journal of the Transportation Research Board (TRR). 93nd Annual Meeting Transportation Research Board (TRB), 12.-16. Jan. 2014, Washington D.C.

26. Garza, AP (2011) "Look Ma, No Hands": Wrinkles and Wrecks in the Age of Autonomous Vehicles. New Eng. L. Rev. 46, 581-615.

27. Goodall NJ (2014). Ethical Decision Making During Automated Vehicle Crashes. In TRB Annual Meeting, Washington DC.

28. Goodall NJ (2014) Machine Ethics and Automated Vehicles. Road Vehicle Automation. Springer, 93-102.

29. Heide A, Henning K (2006) The "cognitive car" : A roadmap for research issues in the automotive sector. Annual reviews in control 30(2), 197-203.

30. Hevelke A, Nida-Rümelin J (2014) Responsibility for Crashes of Autonomous Vehicles: An Ethical Analysis. Science and Engineering Ethics, 1-12.

31. Huijnen C, Badii A, van den Heuvel H, Caleb-Solly P, Thiemert D (2011) Maybe it becomes a buddy, but do not call it a robot-seamless cooperation between companion robotics and smart homes. In Ambient Intelligence. Springer Berlin Heidelberg, 324-329.

32. IHS Automotive (2014) Automotive Technology Research. Emerging Technologies, Autonomous Cars - Not if, but when. http://orfe.princeton.edu/ alaink/SmartDrivingCars/ PDFs/IHS\%20_EmergingTechnologies_AutonomousCars.pdf, last accessed on July $25^{\text {th }} 2014$.

33. Keller KL (1993) Conceptualizing, measuring, and managing customer-based brand equity. Journal of Marketing 57(1), 1-22.

34. Keller KL (2012) Strategic Brand Management - Building, Measuring, and Managing Brand Equity, 4th revised edition. Prentice Hall, Upper Saddle River, New Jersey.

35. Khan AM, Bacchus A, Erwin S (2012) Policy challenges of increasing automation in driving. IATSS research 35(2), 79-89.

36. KPMG (2012) Self-Driving Cars-The next revolution. http://www.kpmg.com/US/en/ IssuesAndInsights/ArticlesPublications/Documents/self-driving-cars-next-revolution.pdf, last accessed on July $25^{\text {th }} 2014$.

37. KPMG (2013) Self-Driving Cars-Are We Ready? http://www.kpmg.com/US/en/Issues AndInsights/ArticlesPublications/Documents/self-driving-cars-are-we-ready.pdf, last accessed on July $25^{\text {th }} 2014$. 
38. Kuo IH, Rabindran JM, Broadbent E, Lee YI, Kerse N, Stafford RMQ, MacDonald BA (2009) Age and gender factors in user acceptance of healthcare robots. In Robot and Human Interactive Communication, 2009. The 18th IEEE International Symposium. Toyama, Japan, 214-219.

39. Lassar W, Mittal B, Sharma A (1995) Measuring customer-based brand equity. Journal of consumer marketing 12 (4), 11-19.

40. Levin IP, Levin, AM (2000) Modeling the Role of Brand Alliances in the Assimilation of Product Evaluations. Journal of Consumer Psychology 9 (1), 43-52.

41. Lin TW, Hwang SL, Green PA (2009) Effects of time-gap settings of adaptive cruise control (ACC) on driving performance and subjective acceptance in a bus driving simulator. Safety Science 47(5), 620-625.

42. Litman T (2014) Autonomous Vehicle Implementation Predictions. Implications for Transport Planning.

43. Lutin JM, Kornhauser AL, Lerner-Lam E (2013) The Revolutionary Development of Self-Driving Vehicles and Implications for the Transportation Engineering Profession. ITE Journal 83 (7), 28-32.

44. Maak N (2014) Googles „Self-Driving Car“ - In welche Zukunft fahren wir? Unter: http://www. faz.net/aktuell/feuilleton/debatten/googles-self-driving-car-wohin-fahren-wir-13002612.html? printPagedArticle=true\#Drucken, last accessed on July 25th 2014.

45. Marchau VAWJ, van der Heijden RECM (1998) Policy aspects of driver support systems implementation: results of an international Delphi study. Transport Policy 5(4), 249-258.

46. Meseko AA (2014) The Influence of Disruptive Innovations in A Cardinally Changing World Economy. Journal of Economics and Sustainable Development 5(4), 24-27.

47. Meuter ML, Ostrom AL, Roundtree RI, Bitner MJ (2000). Self-Service Technologies: Understanding Customer Satisfaction with Technology-Based Service Encounters. Journal of Marketing 64(3), 50-64.

48. Meyer G, Beiker S (2014) Road Vehicle Automation. Heidelberg.

49. Oestreicher L, Eklundh KS (2006) User Expectations on Human-Robot Co-operation. In Robot and Human Interactive Communication, 2006. ROMAN 2006. The 15th IEEE International Symposium, 91-96.

50. Özgüner Ü, Stiller C, Redmill K (2007) Systems for Safety and Autonomous Behavior in Cars: The DARPA Grand Challenge Experience. Proceedings of the IEEE 95(2), 397-412.

51. Payre W, Cestac J, Delhomme P (2014) Intention to use a fully automated car: Attitudes and a priori acceptability. Transportation Research Part F, in press.

52. Rakotonirainy A, Soro A, Schroeter R (2014) Social Car Concepts to Improve Driver Behaviour. Pervasive and Mobile Computing.

53. Rao AR, Qu L, Ruekert, RW (1999) Signaling Unobservable Product Quality Through a Brand Ally. Journal of Marketing Research 36(2), 258-268.

54. Reddy R (1996) The Challenge of Artificial Intelligence. Computer 29 (10), 86-98.

55. Reece DA (1992) Selective Perception for Robot Driving (No. CMU-CS-92-139), Doctoral Thesis in the field of Computer Science, School of Computer Science. Carnegie Mellon University, Pittsburgh.

56. Rupp JD, King AG (2010). Autonomous Driving-A Practical Roadmap (No. 2010-01-2335). SAE Technical Paper.

57. Schaefers T (2013) Exploring Carsharing Usage Motives: A Hierarchical Means-End Chain Analysis. Transportation Research Part A: Policy and Practice 47(1), 69-77.

58. Seidel M, Loch CH, Chahil S (2005) Quo Vadis, Automotive Industry? A Vision of Possible Industry Transformations. European Management Journal 23(4), 439-449.

59. Silverman SN, Sprott DE, Pascal VJ (1999) Relating consumer-based sources of brand equity to market outcomes. Advances in Consumer Research 26, 352-358. 
60. Simon F, Usunier JC (2007) Cognitive, demographic, and situational determinants of service customer preference for personnel-in-contact over self-service technology. International Journal of Research in Marketing 24 (2), 163-173.

61. Simonin BL, Ruth JA (1998) Is a Company Known by the Company it Keeps? Assessing the Spillover Effects of Brand Alliances on Consumer Brand Attitudes. Journal of Marketing Research 35 (1), 30-42.

62. Soriano BC, Dougherty SL, Soublet BG, Triepke KJ (2014) Autonomous Vehicles: A Perspective from the California Department of Motor Vehicles. In Road Vehicle Automation, Springer International Publishing, 15-24.

63. Trimble TE, Bishop R, Morgan JF, Blanco M (2014) Human factors evaluation of level 2 and level 3 automated driving concepts: Past research, state of automation technology, and emerging system concepts. (Report No. DOT HS 812 043). Washington, DC: National Highway Traffic Safety Administration.

64. Vahidi A, Eskandarian A (2003) Research Advances in Intelligent Collision Avoidance and Adaptive Cruise Control. Intelligent Transportation Systems, IEEE Transactions on 4(3), 143-153.

65. Venkatesh V, Morris MG, Davis FD, Davis GB (2003) User Acceptance of Information Technology: Toward a Unified View. MIS Quarterly, 27 (3), 425-478.

66. Wallace R (2013) Self-Driving Cars: The Next Revolution. Global Symposium on Connected Vehicles (5-8 August), Traverse City Michigan USA.

67. Weijters B, Rangarajan D, Falk T, Schillewaert N. (2007) Determinants and Outcomes of Customers' Use of Self-Service Technology in a Retail Setting. Journal of Service Research 10 (1), 3-21.

68. Woisetschläger D, Michaelis M, Backhaus C (2008) The "Dark Side" of Brand Alliances: How the Exit of Alliance Members Affects Consumer Perceptions. Advances in Consumer Research 35, 483-490.

69. Wünderlich N (2010) Acceptance of Remote Services: Perception, Adoption, and Continued Usage in Organizational Settings. Springer-Verlag, Berlin Heidelberg New York.

70. Wünderlich N, Wangenheim F, Bitner MJ (2012) High Tech and High Touch: A Framework for Understanding User Attitudes and Behaviors Related to Smart Interactive Services. Journal of Service Research 16 (1), 3-20.

71. Zhu Z, Nakata C, Sivakumar K, Grewal D (2007) Self-service technology effectiveness: the role of design features and individual traits. Journal of the Academy of Marketing Science 35(4), 492-506. 